\title{
La memoria en la Ley de Víctimas en Colombia: derecho y deber
}

Este artículo se encuentra disponible para su descarga gratuita en www.anuariocdh.uchile.cl

\section{Catalina Uprimny Salazar}

Abogada de la Pontificia Universidad Javeriana y de la Universidad del País Vasco. Estudiante de Doctorado en Derecho en la Universidad del Rosario en Bogotá, Colombia. Consultora del Grupo de Memoria Histórica de la Comisión Nacional de Reparación y Reconciliación de Colombia.

catalina.uprimny@urosario.edu.co

\section{RESUMEN}

En el artículo se comparten algunas reflexiones sobre la memoria en la llamada Ley de Víctimas en Colombia. Se analiza en un primer momento en qué medida la Ley de Víctimas garantiza el derecho a la memoria, tomando como marco teórico el contenido y alcance de este derecho tal como ha sido desarrollado por la Corte Interamericana de Derechos Humanos, y que debe comprender tanto una dimensión individual como una colectiva. Se sostiene que esta Ley tiene problemas de sistematicidad, y que no permite garantizar debidamente la dimensión individual del derecho a la memoria. En una segunda parte, se analiza el deber de memoria del Estado establecido en la Ley, el que, a juicio de la autora, no incorpora debidamente la perspectiva de las víctimas.

Palabras clave: Memoria - Derecho - Deber Víctimas - Colombia

\section{SUMMARY}

The article shares some thoughts regarding memory in the so-called Law on Victims in Colombia. First, the article contains an analysis of the extent to which the Law on Victims ensures the right to memory, taking as a theoretical framework the content and extent of this right as it has been developed by the Inter-American Court on Human Rights, and that should encompass both an individual and a collective dimension. The article argues that this Law is not systematic enough and that it does not allow for the individual dimension of the right to memory to be properly ensured. Thereafter, the article analyzes the duty of memory established by the Law, which -in the opinion of the author-does not properly incorporate the victims' perspective.

Key words: Memory - Right - Duty - Victims - Colombia

"Lo que todas las víctimas necesitan, sobre todo, es saber que no están solas; que no las estamos olvidando, que cuando sus voces sean ahogadas debemos prestarles las nuestras, que mientras su libertad dependa de la nuestra, la calidad de nuestra libertad depende de la suya" -Palabras de Elie Wiesel al aceptar el Premio Nobel de la Paz en 1986

\section{Introducción}

En el presente artículo quisiera compartir algunas reflexiones sobre la memoria en la Ilamada Ley de Víctimas en Colombia, adoptada en junio de 2011 . Las reflexiones estarán enfocadas exclu-

* El presente artículo fue presentado parcialmente como ponencia en la VI versión del seminario "Voces Ausentes: Memoria la Voz de las Víctimas" organizado por la Facultad de Comunicación Social para la Paz de la Universidad Santo Tomás, Colombia, el 22 de septiembre de 2011.

1 Ley No. 1.448 de 2011 por la cual se Dictan Medidas de Atención, Asistencia y Reparación Integral a las Víctimas del Conflicto Armado Interno y se Dictan otras Disposiciones. Congreso de la República de Colombia, 10 de junio de 2011. De ahora en adelante "Ley de Víctimas" o "Ley No. 1.448 de 2011". 
sivamente a la normatividad más reciente sobre el derecho a la memoria en el país y tratarán dos puntos: el primero, la memoria como derecho y, el segundo, la memoria como deber. El análisis que me dispongo a hacer es normativo, es decir, se desprende del contenido de las disposiciones legales, de su ubicación y de sus posibles contradicciones y confusiones.

\section{El derecho a la memoria}

\subsection{Las dos dimensiones del derecho a la memoria}

Tatiana Rincón determina que la primera pregunta que hay que hacerse frente al derecho a la memoria es la relativa a de qué tipo de derecho estamos hablando. Esto es, si se trata de un derecho autónomo o de uno integrado en otros derechos ${ }^{2}$. En particular, es necesario aclarar la relación del derecho a la memoria con el derecho a las medidas de reparación, por un lado y, por otro, con las medidas de no repetición de las violaciones a los derechos humanos.

El derecho a la memoria ha sido estudiado por la Corte Interamericana de Derechos Humanos (en adelante "la Corte IDH" o "la Corte"). Es justamente ella la que puede aclarar el concepto, fundamento y alcance del derecho, y que permitirá evaluar su reciente desarrollo en el ordenamiento jurídico colombiano.

La Corte en su jurisprudencia ha ordenado a los Estados adoptar medidas para la preservación de la memoria de las víctimas como parte de la reparación y también ha ordenado medidas para la preservación de la memoria histórica ${ }^{3}$. Rincón establece que es importante esta diferenciación pues las segundas medidas, las de preservación de la memoria histórica, buscan también contribuir a la no repetición de los hechos ${ }^{4}$. En efecto, la Corte distingue entre la finalidad de contribuir a la reparación de la víctima y la que busca la no repetición. Se trata de dos tipos de fines que el derecho a la memoria puede perseguir, pero el uno no se diluye en el otro, aunque una misma medida pueda, en ocasiones, alcanzar ambos fines. En palabras de Rincón, "el derecho a la memoria no colapsa en la pretensión de no repetición ni, por lo tanto, en las Ilamadas garantías de no repetición" ${ }^{\prime 5}$. La Corte IDH estableció esta diferencia con mucha claridad en el caso Anzualdo Castro vs. Perú en el que consideró que la construcción del Museo de la Memoria, si bien era significativa en la construcción de la memoria histórica y como medida de no repetición, no lo era como medida individual de satisfacción y se ordenaron medidas de memoria individual ${ }^{6}$.

2 RINCÓN, Tatiana. "El derecho humano a la memoria: de la ética a los derechos humanos y de los derechos humanos a la ética". Ponencia dictada en la Cátedra Ciro Angarita Barón de la Defensoría del Pueblo de Colombia, el 11 de noviembre de 2010, p. 17.

3 Cfr. Corte IDH, Caso Manuel Cepeda Vargas vs. Colombia. Excepciones Preliminares, Fondo, Reparaciones y Costas. Sentencia de 26 de mayo de 2010. Serie C No. 213, párr. 228; Caso Chitay Nech vs. Guatemala. Excepciones Preliminares, Fondo, Reparaciones y Costas. Sentencia de 25 de mayo de 2010. Serie C No. 212, párrs. 248 y 251; Caso Radilla Pacheco vs. México. Excepciones Preliminares, Fondo, Reparaciones y Costas. Sentencia de 23 de Noviembre de 2009. Serie C No. 209, párr. 356; Caso González y otras ("Campo Algodonero") vs. México. Excepción Preliminar, Fondo, Reparaciones y Costas. Sentencia de 16 de noviembre de 2009. Serie C No. 205, párrs. 469 y 471; Caso Masacre de las Dos Erres vs. Guatemala. Excepción Preliminar, Fondo, Reparaciones y Costas. Sentencia de 24 de noviembre de 2009. Serie C No. 211, párr. 265; Caso Anzualdo Castro vs. Perú. Excepción Preliminar, Fondo, Reparaciones y Costas. Sentencia de 22 de Septiembre de 2009. Serie C No. 202, párr. 198, 200 y 201; Caso Goiburú y otros vs. Paraguay. Fondo, Reparaciones y Costas. Sentencia de 22 de septiembre de 2006. Serie C No. 153, párrs. 173 y 177. Casos citados por RINCÓN, Tatiana. "El derecho humano a la memoria...", op. cit., p. 6

4 RINCÓN, Tatiana. "El derecho humano a la memoria...", op. cit., p.6.

Ibídem, p. 10.

6 Corte IDH. Caso Anzualdo Castro, op. cit., párr. 200. 
Si se quiere, se puede incluso hablar de dimensiones individuales y colectivas del derecho a la memoria, siendo la memoria individual la encaminada a la reparación de la víctima y la colectiva la relativa a la memoria histórica, las garantías de no repetición y para la sociedad en general (incluidas las víctimas, claro está).

Es fundamental realizar claramente esta diferenciación pues, como explica Pablo de Greiff, "la víctima no pierde su condición de fin en sí misma y no es instrumentalizada para favorecer, a futuro, la no repetición" ${ }^{\prime 7}$. En otras palabras, es esencial tener claro qué tipo de fin se está implementando con determinada medida para garantizar el derecho a la memoria en todas sus dimensiones. Esto, para que no se desarrollen medidas de no repetición como únicas medidas de reparación individual, en perjuicio de las víctimas. $\mathrm{O}$, para que las medidas de reparación a las víctimas no sean a su vez, las únicas medidas de no repetición.

A la luz de este marco teórico es que procederemos a analizar la forma en que el ordenamiento jurídico colombiano y específicamente la recientemente aprobada Ley de Víctimas ha abordado el derecho a la memoria.

\subsection{El derecho a la memoria en el ordenamiento jurídico colombiano}

\section{a. El derecho a la memoria antes de la Ley de Víctimas}

En Colombia, el 20 de agosto de 2010, por primera vez se reconoció en una ley a la memoria como un derecho. La Ley No. 1.408 por la cual se rinde homenaje a las víctimas del delito de desaparición forzada y se dictan medidas para su localización e identificación, regula la creación de lugares de la memoria (santuarios) y adopta varias medidas de conmemoración, pero no establece el alcance del derecho. En esta ley se nombra a la memoria como un derecho tan importante como el de la verdad y el de la vida. Así, se establece que:

[...l]os establecimientos educativos públicos y privados y las autoridades nacionales, departamentales y municipales rendirán homenaje a estas víctimas [de desaparición forzada] esta semana [la última de mayo] con la realización de foros, conferencias, talleres y jornadas de reflexión referentes al derecho a la memoria, a la verdad, a la vida y al respeto por los derechos humanos ${ }^{8}$.

La Ley No. 1.408 de 2010 es un importante antecedente en el análisis del derecho a la memoria en la Ley de Víctimas aprobada en 2011, por cuanto además de consolidar el traslado de la discusión sobre la memoria del plano ético al plano jurídico, nos puede ayudar a establecer el alcance y contenido que tiene ese derecho en el ordenamiento colombiano.

Un antecedente fundamental a la pregunta de si el derecho a la memoria se considera como un derecho autónomo o bien integrado a otros derechos -según la terminología de Rincón- parece estar dada incluso antes, desde la misma Ley No. 975 de 2005 -la Ilamada Ley de Justicia y Pazque en su artículo $8^{\circ}$ sobre el derecho a la reparación, determina que por "reparación simbólica" se entiende toda prestación realizada a favor de las víctimas o de la comunidad en general que

7 DE GREIFF, Pablo. "El deber de recordar ¿el peso muerto del pasado o el peso de los muertos del pasado?" En: HERRERA, María y DE GREIFF, Pablo (Comp.). Razones de la justicia. Homenaje a Thomas McCarthy. México: UNAM-Instituto de investigaciones filosóficas, 2005, pp. $191-221$.

8 Artículo 14 de la Ley No. 1.408 de 2010 por la cual se rinde Homenaje a las Víctimas del Delito de Desaparición Forzada y se Dictan Medidas para su Localización e Identificación. Congreso de la República de Colombia, 20 de agosto de 2010. Negritas agregadas. 
tienda a asegurar, entre otras, la preservación de la memoria histórica ${ }^{9}$. En otras palabras, lo que cinco años más adelante sería reconocido como derecho a la memoria, se entendía como un derecho integrado al de reparación de las víctimas. Aunque en la Ley de Justicia y Paz no se consideró a la memoria como un derecho (ni siquiera integrado a otro derecho), sino como una medida de reparación, la naturaleza y alcance que tendría en el ordenamiento colombiano se empezó a direccionar desde entonces.

La Ley de Justicia y Paz de 2005 y la Ley No. 1.408 de 2010 contemplan por tanto antecedentes sobre el contenido y alcance del derecho a la memoria en el derecho colombiano. A continuación analizaremos específicamente la forma en que este derecho es consagrado en la Ley de Víctimas de 2011. Veremos que esta regulación es poco sistemática e incompleta, en tanto la ubicación del derecho a la memoria en la estructura de la ley haría pensar que este derecho se va a abordar únicamente desde la perspectiva individual, sin embargo, cuando se estudia el contenido de las disposiciones, es posible observar que solamente se consideran medidas de alcance colectivo.

\section{b. El problema de sistematización: la ubicación del derecho a la memoria en la Ley de Víctimas}

La Ley de Víctimas de 2011 ubica las disposiciones sobre la memoria en el capítulo IX relativo a las medidas de satisfacción, definiendo estas últimas como una de las medidas de la reparación integral ${ }^{10}$. Es decir, las medidas de satisfacción tienen como objeto la reparación. Y, por su parte, dicho capítulo contiene un acápite que contiene las únicas disposiciones sobre la memoria en la Ley. Conclusión: aparentemente en la Ley de Víctimas la memoria cumpliría fines exclusivamente de reparación y atendería por tanto a la dimensión individual del derecho a la memoria.

Esto se ve reafirmado por el hecho que, en la Ley de Víctimas, el capítulo que corresponde al de las garantías de no repetición se encuentra separado de las medidas de satisfacción y en él no se contemplan disposiciones relativas a la memoria.

Efectivamente, este capítulo que se compone de dos artículos, comprende las medidas que el Estado colombiano adoptará para que los hechos de victimización no vuelvan a ocurrir. Es así como en el artículo 149 se enuncian 19 medidas que se implementarán mediante el fortalecimiento de planes y programas que conforman la política pública de prevención y protección; y en el artículo siguiente se proponen (sin mencionar cuáles son) medidas para el "desmantelamiento de las estructuras económicas y políticas que se han beneficiado y que han dado sustento a los grupos armados al margen de la ley"11. Sin embargo, no existe mención alguna a la memoria, ni como medida, ni como fin.

Luego, de la ubicación de las disposiciones de memoria histórica en la Ley en el marco de las medidas de satisfacción y del contenido del capítulo de medidas de no repetición, se desprende que en la Ley de Víctimas, el derecho a la memoria no tendría la dimensión colectiva que evitaría la repetición de los hechos. De la ubicación que tienen las disposiciones sobre memoria en la Ley de Víctimas, podría entonces esperarse que las disposiciones sobre el derecho a la memoria fueran a tratar únicamente de medidas para la reparación de las víctimas a nivel individual.

\footnotetext{
9 Ley No. 975 de 2005 por la cual se dictan disposiciones para la reincorporación de miembros de Grupos Armados Organizados al Margen de la Ley, que Contribuyan de Manera Efectiva a la Consecución de la Paz Nacional y se dictan otras disposiciones para Acuerdos Humanitarios. Congreso de la República de Colombia, 25 de julio de 2005. De ahora en adelante "Ley No. 975 de 2005" o "Ley de Justicia y Paz".

10 Artículo 25 de la Ley No. 1.448 de 2011.

11 Artículo 150 de la Ley No. 1.448 de 2011.
} 
Procedamos entonces a analizar si efectivamente las disposiciones del capítulo sobre las medidas de satisfacción corresponden a medidas de reparación de las víctimas y, por lo tanto, a la memoria individual.

c. El contenido real del derecho a la memoria en la Ley de Víctimas: el olvido de la dimensión individual de este derecho

Comencemos el análisis del siguiente enunciado: si, como sostiene Tatiana Rincón, el derecho a la memoria es un derecho a una medida de reparación, obviamente su fin sería la reparación del derecho violado y su alcance solo cubriría a las víctimas como titulares privilegiadas al derecho a la reparación.

En la Ley no encuentro completa correspondencia con estas condiciones, lo que puede significar que se estén confundiendo los fines de las medidas de memoria que se implementan, con el riesgo de creer satisfecho el derecho de las víctimas a la memoria individual (como reparación) con la memoria histórica (como garantía de no repetición). Veamos.

El artículo 142 establece que el 9 de abril de cada año se celebrará el Día de la Memoria y Solidaridad con las Víctimas y se realizarán, por parte del Estado colombiano, eventos de memoria y reconocimiento de los hechos que han victimizado a los colombianos y colombianas. Asimismo, el Congreso de la República se reunirá en pleno ese día para escuchar a las víctimas en una jornada de sesión permanente, como medida de reparación y con el fin exclusivo de ayudar a reparar el dolor que las víctimas han sufrido y los años que posiblemente han tenido que callar.

En otra sección de la Ley, el artículo 196 establece disposiciones relacionadas con las medidas de satisfacción y reparación simbólica a las que están obligados quienes se hubieren beneficiado de las medidas de indulto, amnistía, auto inhibitorio, preclusión de la investigación o cesación de procedimiento en 1991. Estas personas estarán obligadas a enaltecer la memoria de sus víctimas a través de la ejecución de las medidas de satisfacción y de reparación simbólica previstas en la Ley.

Hasta acá podría haber concordancia con medidas de memoria orientadas a la reparación individual, pero en los siguientes artículos se evidencia que la reparación de las víctimas no es el principal objetivo del derecho a la memoria en la Ley.

En efecto, la Ley crea el Centro de Memoria Histórica cuyo objeto es reunir y recuperar todo el material documental, testimonios orales, entre otros, relativos a las infracciones al Derecho Internacional Humanitario y violaciones de los derechos humanos. La información recogida será puesta a disposición de los interesados, de los investigadores y de los ciudadanos en general, mediante actividades museísticas, pedagógicas y cuantas sean necesarias "para proporcionar y enriquecer el conocimiento de la historia política y social de Colombia"12. La Ley determina que la memoria del Centro de Memoria, se destinaría a la sociedad para que se tenga conocimiento de los hechos de su pasado y, aunque no lo dice expresamente, se podría presumir que el objetivo de este conocimiento sería la reflexión social encaminada a prevenir la repetición de los hechos.

Entre las funciones del Centro de Memoria Histórica, están las de diseñar, crear y administrar un Museo de la Memoria con el objetivo específico de lograr el fortalecimiento de la memoria colectiva acerca de los hechos desarrollados en la historia reciente de la violencia en Colombia ¿Para qué? De nuevo, y aunque no lo dice la Ley, se puede inferir que para conocer, reflexionar y en últimas evitar que vuelva a ocurrir.

12 Artículo 147 de la Ley No. 1.448 de 2011. 
Otra función es la relativa a la administración del Programa de Derechos Humanos y Memoria Histórica que se encarga del acopio, preservación y custodia de los materiales que recoja o sean entregados, que se refieran o documenten todos los temas relacionados con las violaciones a los derechos humanos o infracciones al Derecho Internacional Humanitario, así como la respuesta estatal de dichas violaciones. Esto en concordancia con la Ley de Justicia y Paz que entendió el deber de memoria del Estado como la conservación de archivos para el conocimiento de las causas, desarrollos y consecuencias de la acción de los grupos armados al margen de la ley ${ }^{13}$. Esta sin duda es una medida de preservación de la memoria histórica.

La última función determinada en la Ley, es la de desarrollar e implementar las acciones en materia de memoria histórica que dan cuenta de que el principal objetivo de ella no parece ser el de la reparación de las víctimas, sino el del conocimiento de la historia del conflicto colombiano.

Diez y ocho días después de ser sancionada la Ley de Víctimas, el Decreto No. 2.244 de 2011, adiciona otras funciones al Centro que complejizan el análisis de su gestión ${ }^{14}$. En el marco de la Ley No. 1.424 de 2010 por la cual se dictan disposiciones de justicia transicional que garanticen la verdad, la justicia y reparación a las víctimas de desmovilizados de grupos al margen de la ley, se conceden beneficios jurídicos y se dictan otras disposiciones ${ }^{15}$, se crea un sistema en el que aquellos desmovilizados (según algunas cifras 17.000 personas ${ }^{16}$ ) cuyo único delito haya sido el de pertenecer al grupo armado al margen de la ley y todo lo que implica (utilización ilícita de uniformes, de armas y de equipos transmisores), podrán realizar un "Acuerdo de Contribución a la Verdad Histórica y a la Reparación" mediante un "mecanismo no judicial de contribución a la verdad y la memoria histórica", que implicará la suspensión de la pena del perpetrador a cambio de la declaración de toda la información que la persona tenga sobre la actividad delictiva que realizó ${ }^{17}$. El Decreto mencionado atribuye esa función al Centro de Memoria Histórica y lo convierte en el operador del mecanismo no judicial de contribución a la verdad y la memoria histórica ${ }^{18}$.

De manera general, las funciones del Centro de Memoria demuestran que éste no se encarga de medidas cuyo fin sea el de la reparación a las víctimas, sino más bien de medidas de memoria histórica para el conocimiento y la reflexión de la historia del conflicto colombiano, constituyéndose, en últimas, en una medida de no repetición de los hechos.

Frente a la indeterminación de la dimensión del derecho a la memoria que trata la Ley, que es expresa (y hasta engañosa pues el capítulo hace parecer que se trata de medidas para garantizar la memoria individual de las víctimas, cuando hemos visto que no es así), se debe ser cuidadoso frente a las confusiones de las dos dimensiones del derecho. No podemos entender que una víctima ha sido reparada simbólicamente porque exista un Centro de Memoria que trata el conflicto colombiano. Las víctimas deberán entonces acudir a instancias judiciales para que, caso por caso, los tribunales y jueces establezcan las medidas adicionales de reparación simbólica para garantizar su derecho a la memoria.

13 Artículo 56 de la Ley No. 975 de 2005.

14 Decreto No. 2.244 de 2011 por el cual se Adicionan unas Funciones al Centro de Memoria Histórica y se dictan otras disposiciones. Ministerio del Interior y de Justicia, República de Colombia, 28 de junio de 2011.

15 Ley No. 1.424 de 2010 por la cual se dictan disposiciones de Justicia Transicional que Garanticen la Verdad, la Justicia y Reparación a las Víctimas de Desmovilizados de Grupos al Margen de la Ley, se conceden Beneficios Jurídicos y se dictan otras disposiciones. Congreso de la República de Colombia, 29 de diciembre de 2010.

16 "'Acuerdos por la verdad' sacarían a ex 'paras' del limbo jurídico". El Tiempo. 27 de noviembre de 2010. [en línea] <http:// www.eltiempo.com/justicia/ARTICULO-WEB-NEW_NOTA_INTERIOR-8464203.html> [consulta: 10 octubre 2011].

17 Artículos 2 y 4 de la Ley No. 1.424 de 2010.

18 Artículo $1^{\circ}$ del Decreto No. 2.244 de 2011. 
Por otro lado, tampoco se cumple en la Ley de Víctimas con un segundo requisito para considerar el derecho a la memoria como derecho individual a la reparación, esto es, no se considera a las víctimas como titulares privilegiadas al derecho a la reparación.

Para analizar este punto hay que determinar qué se entiende por víctimas y quiénes lo son en la Ley de Víctimas. El artículo $3^{\circ}$ establece que se consideran víctimas aquellas personas que individual o colectivamente hayan sufrido un daño por hechos ocurridos a partir del $1^{\circ}$ de enero de 1985, como consecuencia de infracciones al Derecho Internacional Humanitario o de violaciones graves y manifiestas a las normas internacionales de Derechos Humanos, con ocasión del conflicto armado interno. Basado en esta definición, la Ley contempla tres marcos temporales con diferentes alcances de reparación para las víctimas:

i) Después de 1991: Las víctimas pueden solicitar la restitución jurídica y material de las tierras despojadas o abandonadas forzadamente, si entre el $1^{\circ}$ de enero de 1991 y el término de vigencia de la Ley (2021) abandonaron sus predios por hechos que configuren violaciones en los términos del artículo $3^{\circ}$.

ii) Desde 1985: Son las víctimas que la ley reconoce con posibilidad de reparación económica, además de la reparación simbólica.

iii) Antes de 1985: Se establece que "[l]as personas que hayan sido víctimas por hechos ocurridos antes del $1^{\circ}$ de enero de 1985 tienen derecho a la verdad, medidas de reparación simbólica y a las garantías de no repetición previstas en la presente ley, como parte del conglomerado social y sin necesidad de que sean individualizadas" ${ }^{\prime 19}$.

Además del reconocimiento de que las víctimas tienen este derecho antes de 1985, la importancia de este parágrafo radica, en que lo pueden reclamar como parte del conglomerado social, es decir, que estos son derechos que la sociedad tiene. La sociedad tiene el derecho de exigir la verdad sobre los hechos violatorios de los derechos humanos, a medidas de reparación simbólica y a garantías de no repetición.

Las medidas de reparación simbólica en la Ley son todas las prestaciones realizadas "a favor de las víctimas o de la comunidad en general que tiendan a asegurar la preservación de la memoria histórica, la no repetición de los hechos victimizantes, la aceptación pública de los hechos, la solicitud de perdón público y el restablecimiento de la dignidad de las víctimas" ${ }^{20}$. ¿Esto significa entonces que las víctimas no serían las únicas titulares del derecho a la memoria como reparación, pues la Ley fusiona la memoria individual de antes de 1985 con la memoria colectiva? No. Esto significa que las medidas enunciadas en la Ley hablan de la dimensión colectiva del derecho a la memoria (memoria histórica), reconociéndolo como derecho de toda la ciudadanía, pero olvidando la necesidad de la memoria individual de las víctimas, especialmente de las anteriores a 1985.

Este punto, relacionado con una conclusión anterior, que mencionaba que las víctimas debían entonces acudir a instancias judiciales para garantizar su derecho a la memoria individual, deja muchas preguntas frente al derecho a la memoria de las víctimas antes de 1985. ¿Podrían acudir a instancias judiciales exclusivamente a reclamar su derecho individual a la memoria? ¿La exigibilidad de este derecho prescribe junto con el delito que lo generó? Este debate debería darse.

Es importante que en la reglamentación de la Ley y del Centro de Memoria exista claridad entre los fines de unas y otras medidas, sus destinatarios y alcances para que ambas dimensiones del

19 Artículo 3, par. 4 de la Ley No. 1.448 de 2011. Negritas agregadas.

20 Artículo 141 de la Ley No. 1.448 de 2011. Negritas agregadas. 
derecho a la memoria puedan verse satisfechas y no se sacrifique a una en la otra. Tanto la dimensión colectiva como la individual son fundamentales y necesarias.

\section{El deber de memoria}

El desarrollo del derecho a la memoria está muy relacionado con el deber de memoria que el Estado ha determinado. Brevemente quisiera compartir también algunas apreciaciones al respecto. La Ley de Víctimas entiende el deber de memoria como "propiciar las garantías y condiciones necesarias para que la sociedad, a través de sus diferentes expresiones tales como víctimas, academia, centros de pensamiento, organizaciones sociales, organizaciones de víctimas y de derechos humanos, así como los organismos del Estado que cuenten con competencia, autonomía y recursos, puedan avanzar en ejercicios de reconstrucción de memoria como aporte a la realización del derecho a la verdad del que son titulares las víctimas y la sociedad en su conjunto". En el parágrafo del mismo artículo se establece que "en ningún caso las instituciones del Estado podrán impulsar o promover ejercicios orientados a la construcción de una historia o verdad oficial que niegue, vulnere o restrinja los principios constitucionales de pluralidad, participación y solidaridad y los derechos de libertad de expresión y pensamiento". También se anuncia que "se respetará también la prohibición de censura consagrada en la Carta Política"21.

Es claro en esta disposición que el deber de memoria tampoco es entendido como una medida de reparación de las víctimas, sino de construcción de memoria histórica. A partir de este artículo además, se podría entender cuál es el modelo de memoria que el Estado está adoptando para la producción de memoria sobre las acciones de violación masiva de los derechos humanos.

Michael Rothberg22 explica que existen tres diferentes modelos posibles. El primer modelo de construcción de memoria sería el liberal. Dicho modelo parte de la premisa de que la construcción de memoria es una labor de la sociedad civil, y la injerencia del Estado en dicha actividad es un atentado contra el principio mismo de libertad personal. El principal efecto de este modelo es que promueve un escenario competitivo de memoria, en el que las diferentes expresiones de la sociedad, como anuncia la Ley, entran a combatir por los acontecimientos violentos más significativos o más dignos de recordar y la consolidación en la memoria de aquellos eventos que pretenden recordar. Esta disputa, como es evidente, no es equilibrada y quienes tienen la mayor cantidad de recursos materiales y simbólicos en la sociedad seguramente se impondrán.

El modelo multidireccional, por otra parte, toma como punto de partida que los agentes que participan en la disputa por la memoria no disponen de los mismos recursos y que, sin acciones de reconocimiento del Estado o de aceptación de la ocurrencia de los hechos, las demandas de memoria de los agentes con menos recursos, están condenadas a desaparecer.

Finalmente está el modelo unidireccional en donde las instituciones del Estado toman una posición activa frente a lo que debe ser recordado. Este ha sido tradicionalmente el modelo de las lógicas negacionistas.

La Ley parece mostrar en la primera parte del artículo 156 un modelo liberal de construcción de memoria donde cada sección de la sociedad tiene la posibilidad de luchar por la memoria, e incluso impide expresamente la posibilidad de la adopción del modelo unidireccional al prohibir ejercicios de memoria que nieguen, vulneren o restrinjan los principios constitucionales de pluralidad, participación y solidaridad y los derechos de libertad de expresión y pensamiento.

21 Artículo 143 de la Ley No. 1.448 de 2011.

22 ROTHBERG, Michael. Multidirectional Memory. Standford: Standford University Press, 2009. 
Sin embargo, no reconoce la desventaja para la construcción de la memoria en la que se encuentran las víctimas, ni la contradicción que supone que diez y ocho días después de la Ley se atribuyan funciones al Centro de Memoria que impliquen la priorización de la memoria de los perpetradores en dicho espacio.

La recomendación en este sentido para reglamentación, sería la de promover acciones en favor de las víctimas fortaleciéndolas mediante un modelo multidireccional de memoria, es decir, uno en el que el Estado tome partido activo en beneficio de la construcción de la memoria de las víctimas. Especialmente cuando lo que debe contarse del pasado solo las víctimas lo saben, pues ellas, al experimentar situaciones límite, son las únicas que tienen el poder de ver las cosas desde otro punto de vista ${ }^{23}$.

\section{Conclusión}

El debate sobre el derecho a la memoria hasta ahora está iniciando en Colombia. Las luces que la Corte Interamericana de Derechos Humanos ha dado sobre el derecho deben guiar el entendimiento del mismo y la forma en que se piensa garantizar plenamente. La Ley de Víctimas es una iniciativa que abre la discusión y pone de manifiesto, en la esfera pública, los retos que se alzan para garantizar el derecho de la memoria de las víctimas.

Sin embargo, es fundamental dejar de manifiesto que la Ley No. 1.448 de 2011 siendo supuestamente una ley de víctimas, fomenta la construcción de una memoria que se enfoca exclusivamente en las medidas de no repetición, no garantizando el derecho a la memoria como medida de reparación para las víctimas. Tampoco proporciona un marco legal claro, obligándolas a acudir a instancias judiciales para ver satisfecho su derecho a la memoria. Consecuentemente, por el deber ético de memoria que como sociedad tenemos, y por el deber jurídico de memoria que tiene el Estado, la memoria que se debe privilegiar es la memoria de las víctimas.

Los jueces y la sociedad deberán tener esto claro para apoyar la causa de las víctimas y que finalmente sus derechos sean plenamente protegidos y garantizados.

No las olvidemos. No lo olvidemos.

Recibido: 31 octubre 2011

Aceptado: 2 febrero 2012

23 BENJAMIN, Walter. Para una crítica de la violencia. México: Premiá Editora S.A., 1978, p. 129. 
